\title{
Spontaneous Resorption Of A Lumbar Disc Herniation In A Patient With Multiple Myeloma: A Rare Association
}

\section{Xingchen Yao}

Beijing Chaoyang Hospital

Yanzhe Wei

Shenzhen People's Hospital

Lei Qi

Beijing Chaoyang Hospital

Xinru Du ( $\nabla$ dxr2013@163.com )

Beijing Chaoyang Hospital

\section{Case report}

Keywords: Multiple myeloma, Disc herniation, Resorption, VEGF

Posted Date: July 20th, 2020

DOI: https://doi.org/10.21203/rs.3.rs-41644/v1

License: (9) This work is licensed under a Creative Commons Attribution 4.0 International License. Read Full License 


\section{Abstract}

Background: The phenomenon of spontaneous resorption of a herniated disc (HD) is a common occurrence. In literature, there are many studies attempting to explain the mechanism for regression, including imaging techniques and immunohistologic analyses. Nevertheless, the exact mechanism remains uncertain. In addition, the connection between HD regression and general conditions of patients is not concerned yet. Here we report a case of spontaneous resorption of a lumbar disc herniation in a patient with multiple myeloma, which had not reported before.

Case presentation: An illustrative patient, a 42-year-old Chinese man, was admitted to our hospital with a disc herniation at $\mathrm{L}_{5}-\mathrm{S}_{1}$, experiencing 2-months history of low back pain and 1-month left leg pain. $\mathrm{He}$ was treated conservatively with medication and physical therapy. Then he was symptom-free after 2 months. The low back pain of the patient recurred with the herniated lumbar disc disappearing after 2 years. The disappearance demonstrated by magnetic resonance imaging (MRI). And besides, the patient was diagnosed with multiple myeloma (MM). The emergence of MM might result in the recurred backache, and the process of HD resorption might be accelerated by the high serum Vascular endothelial growth factor (VEGF) of the MM patient.

Conclusions: For patients who suffering from intervertebral disc herniation together with diseases upregulating VEGF level, such as MM, surgical treatment should be limited and the conservatively treating time can be lengthened.

\section{Background}

Spontaneous resorption of herniated disc (HD) is a well-known occurrence which the herniated nucleus pulposus shrink or even disappear spontaneously without invasive therapy. A lot of similar cases have been presented ever since Guinto first reported a case of spontaneous resorption of HD at lumbar spine in 1984 , which demonstrated by computed tomography (CT $)^{[1]}$. The underlying mechanism remains unclear despite the fact that numerous studies have been done by researchers. Unfortunately, most of researchers pay close attention to local situations of patients whose HDs are diminished, and the general conditions of patients are ignored ${ }^{[2-4]}$. In our study, the spontaneous disc resorption of a patient with multiple myeloma (MM) has been presented and the clinical significance has been discussed.

\section{Case Presentation}

\section{Chief complaints}

A 42-year-old Chinese male patient experienced 2-months history of low back pain and 1-month left leg pain with no obvious cause.

\section{History of past illness}


The patient had a free previous medical history.

\section{Personal and family history}

He denied any other family history.

\section{Physical examination upon admission}

Neurological examination was decreased sensation of touch in the left lateral calf and was neither motor deficit nor cauda equine lesion. Furthermore, the straight-leg-raising test was positive on the left side $\left(30^{\circ}\right)$ and Knee-jerk Reflex together with Achilles-jerk Reflex was normal.

\section{Imagingexaminations}

A MRI examination of lumbar spine suggested the presence of a $\mathrm{HD}$ at $\mathrm{L}_{5}-\mathrm{S}_{1}$ level on the left side and the left nerve root was seen to be compressed by the HD (Fig.1).

\section{Preliminary diagnosis and treatment}

Based on the clinical symptom $\otimes$ Physical examination and the computed tomography finding of herniated disc at L5-S1 level, a diagnosis of lumber disc herniation was made. The patient chose to have conservative ways including physical and medical therapies and was symptom-free after 2 months.

\section{Outcome and follow-up}

However, the patient returned 6 months later with the complaint of recurred low back pain, which aggravating during the night. Follow-up MRI images showed complete disappearance of the extruded HD that had been found at $\mathrm{L}_{5}-\mathrm{S}_{1}$ level and there were many inhomogeneous MRI signals within spinal centrums (Fig.2). The patient was diagnosed with multiple myeloma (MM) according to the results of bone marrow puncture and determination of M-protein. The plasmacyte was $7.5 \%$ indicated by bone marrow biopsy, and all of them were immature (Fig.3). As the immunoreactive electrophoresis identified, the component of the monoclonal protein was $\lambda$ light chain, and the background protein was decreased. Besides, the 24 hours of the $M$ protein was $1.232 \mathrm{~g}$ and $\beta_{2}$ microglobulin was $3.82 \mathrm{mg} / \mathrm{L}$.

\section{Final diagnosis and treatment}

Finally, the patient was diagnosed with multiple myeloma and resorption of the herniated disc occurred. Patient was transferred to hematology department to accept further treatment.

\section{Discussion}

The spontaneous resorption of HD in a patient treated non-operatively is a well-documented phenomenon, which is observed at almost all spinal compartments, cervical, thoracic, and lumbar ${ }^{[5-7]}$. There were $42.5 \%$ enrolled patients (68 of 160 ) with spontaneous regression of HD demonstrated by MRI 
within 2 months in the study by Autio ${ }^{[8]}$. In other researches, the occurrence of spontaneous resorption of HD was about $35 \%-63 \%$ over 6 months to 1 year ${ }^{[8,9]}$.

Many a theory exist to explain the mechanism behind the spontaneous regression of HD, including dehydration theory, retraction theory with the retraction of posterior longitudinal ligament (PLL), resorption theory with macrophage phagocytosis ${ }^{[7,10-12]}$. In the third theory, neovascularization of HD plays an important role in resorption process with VEGF (vascular endothelial growth factor) assistance. VEGF, a highly specific mitogen for endothelial cell, plays an indispensable role in the formation of newborn blood vessels, containing the differentiation of angioblasts and the subsequent formation of vascular tubules ${ }^{[13]}$. Moreover, capillaries that invade the hernia are regarded as essential factors in resorption of the $\mathrm{HD}^{[14]}$. On the other hand, VEGF is an effective inducer of plasmin through plasminogen activators (PAs). Plasmin activates MMPs, which are necessary for the matrix degradation that occurs during the HD resorption process ${ }^{[15]}$. Obviously, VEGF plays a crucial role in the process of spontaneous regression of HD. It's well-known that VEGF is really highly expressed in serum of MM patients ${ }^{[16,17]}$. Myeloma cells can directly secrete VEGF, which combing with VEGF-2 receptors, facilitating the process of new-born capillaries formation. Thus we can suppose the HD resorption process of the patient have connections, to some extent, with the high VEGF level due to MM.

Disc herniation was categorized into three types by Komori, comprising intact disc margin (type 1), discontinuous disc margin (type 2), and extrusion beyond the height of the disc (type 3$)^{[18]}$. In their study, the further the HD migrated, mean type 3 , the more decrease degree could be observed, and type 1 showed few or even no variation on follow-up MR ${ }^{[9]}$. Henmi noticed that the larger the disc fragments protruded, the more they diminished ${ }^{[19]}$. Ahn considered that the exposure of HD materials to the epidural vascular supply through the ruptured PLL might facilitate the resorption progress ${ }^{[20]}$.

On the contrary, the HD in the case we performed diminished thoroughly even if it's only a medium or small size, non-sequestrated, subligamentous herniation. We can presume the abnormal phenomenon is related to the special general conditions of the MM patient, which have relatively higher level of serum VEGF.

\section{Conclusions}

The likelihood of spontaneous resorption of HD can be estimated approximately by making use of enhanced imaging together with the Komori classification ${ }^{18}$. However, for patients suffering from intervertebral disc herniation together with diseases upregulating VEGF level, such as MM, surgical treatment should be limited and the conservatively treating time can be lengthened as long as no severe neurological deficits or intractable low back and leg pain exist, even though the possibility of spontaneous resorption of HD is not high enough assessed by former methods.

\section{List Of Abbreviations}


HD: Herniated disc

MM: Multiple myeloma

MRI: Magnetic resonance imaging

VEGF: Vascular endothelial growth factor

CT: Computed tomography

PLL: Posterior longitudinal ligament

PAs: Plasminogen activators

\section{Declarations}

\section{Ethics approval and consent to participate}

Beijing Chao-yang Hospital Human Research Ethics Committee classifies

this as a retrospective audit and, as such, does not require ethics

submission/approval nor consent to participate.

Consent for publication

Beijing Chao-yang Hospital Human Research Ethics Committee classifies this as a retrospective audit and, as such, does not require consent to publish.

\section{Availability of data and materials}

The datasets during and/or analysed during the current study are available

from the corresponding author on reasonable request.

\section{Competing interests}

The authors declare that they have no competing interests.

\section{Funding}

There is no funding source.

\section{Authors' contributions}


$\mathrm{XCY}$ is the primary author and contributed in drafting and revising the manuscript. YZW/LQ contributed to the data collection and drafting of the manuscript. XRD contributed to the conception of the article and manuscript revision. All authors read and approved the final manuscript.

\section{Ackonwledgements}

We wish to thank Dr Lihong-Li and Dr Wenming-Chen, of Beijing Chao-Yang hospital Hematology Dept, for them help in statistical analysis and processing.

\section{References}

1. Guinto FC Jr, Hashim H, Stumer M. CT demonstration of disk regression after conservative therapy. AJNR American journal of neuroradiology 1984;5:632-633 [PMID: 6435432]

2. Autio RA, Karppinen J, Kurunlahti M, Haapea M, Vanharanta H, Tervonen O. Effect of periradicular methylprednisolone on spontaneous resorption of intervertebral disc herniations. Spine 2004;29:1601-1607 [PMID: 15284501 DOI: 10.1097/01.brs.0000132511.46818.67]

3. Geiss A, Larsson K, Rydevik B, Takahashi I, Olmarker K. Autoimmune properties of nucleus pulposus: an experimental study in pigs. Spine 2007;32:168-173 [PMID: 17224810 DOI:

10.1097/01.brs.0000251651.61844.2d]

4. Yoshida M, Nakamura T, Sei A, Kikuchi T, Takagi K, Matsukawa A. Intervertebral disc cells produce tumor necrosis factor alpha, interleukin-1 beta, and monocyte chemoattractant protein-1 immediately after herniation: an experimental study using a new hernia model. Spine 2005;30:55-61 [PMID: 15626982 DOI: 10.1097/01.brs.0000149194.17891.bf]

5. Stavrinou LC, Stranjalis G, Maratheftis N, Bouras T, Sakas DE. Cervical disc, mimicking nerve sheath tumor, with rapid spontaneous recovery: a case report. European spine journal : official publication of the European Spine Society, the European Spinal Deformity Society, and the European Section of the Cervical Spine Research Society 2009;18 Suppl 2:176-178 [PMID: 18781343 DOI: 10.1007/s00586008-0765-z]

6. Coevoet V, Benoudiba F, Lignieres C, Said G, Doyon D. [Spontaneous and complete regression in MRI of thoracic disk herniation]. Journal de radiologie 1997;78:149-151 [PMID: 9113161]

7. Yang X, Zhang Q, Hao X, Guo X, Wang L. Spontaneous regression of herniated lumbar discs: Report of one illustrative case and review of the literature. Clinical neurology and neurosurgery 2016;143:8689 [PMID: 26907997 DOI: 10.1016/j.clineuro.2016.02.020]

8. Autio RA, Karppinen J, Niinimaki J, Ojala R, Kurunlahti M, Haapea M, Vanharanta H, Tervonen O. Determinants of spontaneous resorption of intervertebral disc herniations. Spine 2006;31:1247-1252 [PMID: 16688039 DOI: 10.1097/01.brs.0000217681.83524.4a]

9. Komori H, Shinomiya K, Nakai O, Yamaura I, Takeda S, Furuya K. The natural history of herniated nucleus pulposus with radiculopathy. Spine 1996;21:225-229 [PMID: 8720408 DOI:

10.1097/00007632-199601150-00013] 
10. Liu JT, Li XF, Yu PF, Li XC, Qian Q, Liu GH, Yu ZH, Ma QH, Tang DZ, Jiang H. Spontaneous resorption of a large lumbar disc herniation within 4 months. Pain physician 2014;17:E803-806 [PMID: 25415803]

11. Kim SG, Yang JC, Kim TW, Park KH. Spontaneous regression of extruded lumbar disc herniation: three cases report. Korean Journal of Spine 2013;10:78-81 [PMID: 24757463 DOI: 10.14245/kjs.2013.10.2.78]

12. Tsuru M, Nagata K, Ueno T, Jimi A, Irie K, Yamada A, Nishida T, Sata M. Electron microscopic observation of established chondrocytes derived from human intervertebral disc hernia (KTN-1) and role of macrophages in spontaneous regression of degenerated tissues. The spine journal : official journal of the North American Spine Society 2001;1:422-431 [PMID: 14588300 DOI: 10.1016/s15299430(01)00055-9]

13. Koike Y, Uzuki M, Kokubun S, Sawai T. Angiogenesis and inflammatory cell infiltration in lumbar disc herniation. Spine 2003;28:1928-1933 [PMID: 12973136]

14. Kobayashi S, Meir A, Kokubo Y, Uchida K, Takeno K, Miyazaki T, Yayama T, Kubota M, Nomura E, Mwaka E, Baba H. Ultrastructural analysis on lumbar disc herniation using surgical specimens: role of neovascularization and macrophages in hernias. Spine 2009;34:655-662 [PMID: 19333096 DOI: 10.1097/BRS.0b013e31819c9d5b]

15. Haro H, Kato T, Komori H, Osada M, Shinomiya K. Vascular endothelial growth factor (VEGF)-induced angiogenesis in herniated disc resorption. Journal of orthopaedic research : official publication of the Orthopaedic Research Society 2002;20:409-415 [PMID: 12038611 DOI: 10.1016/S07360266(01)00150-4]

16. Giuliani N, Storti P, Bolzoni M, Palma BD, Bonomini S. Angiogenesis and multiple myeloma. Cancer microenvironment : official journal of the International Cancer Microenvironment Society 2011;4:325337 [PMID: 21735169 DOI: 10.1007/s12307-011-0072-9.]

17. Brito AB, Lourenco GJ, Oliveira GB, De Souza CA, Vassallo J, Lima CS. Associations of VEGF and VEGFR2 polymorphisms with increased risk and aggressiveness of multiple myeloma. Annals of hematology 2014;93:1363-1369 [PMID: 24687381 DOI: 10.1007/s00277-014-2062-8]

18. Kim ES, Oladunjoye AO, Li JA, Kim KD. Spontaneous regression of herniated lumbar discs. Journal of clinical neuroscience : official journal of the Neurosurgical Society of Australasia 2014;21:909-913 [PMID: 24316264 DOI: 10.1016/j.jocn.2013.10.008]

19. Henmi T, Sairyo K, Nakano S, Kanematsu Y, Kajikawa T, Katoh S, Goel VK. Natural history of extruded lumbar intervertebral disc herniation. The journal of medical investigation : JMI 2002;49:40-43 [PMID: 11901758]

20. Ahn SH, Ahn MW, Byun WM. Effect of the transligamentous extension of lumbar disc herniations on their regression and the clinical outcome of sciatica. Spine 2000;25:475-480 [PMID: 10707394 DOI: $10.1097 / 00007632-200002150-00014]$

\section{Figures}



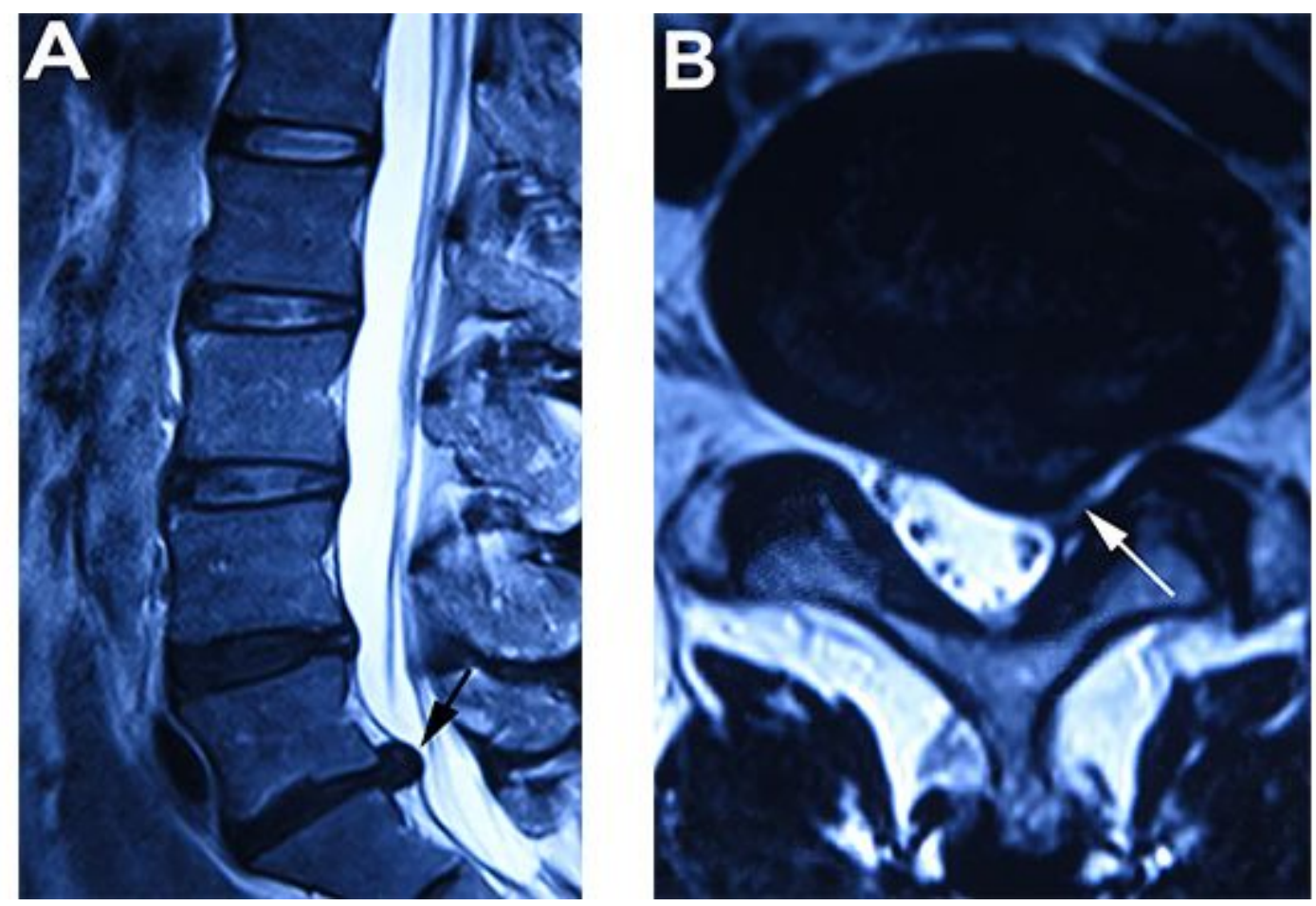

\section{Figure 1}

Sagittal (A) and Axial (B) T2-weighted MRI of the lumbar spine images show a medium extruded disc herniation on the left side (white arrowhead) at the L5-S1 level (black arrowhead).
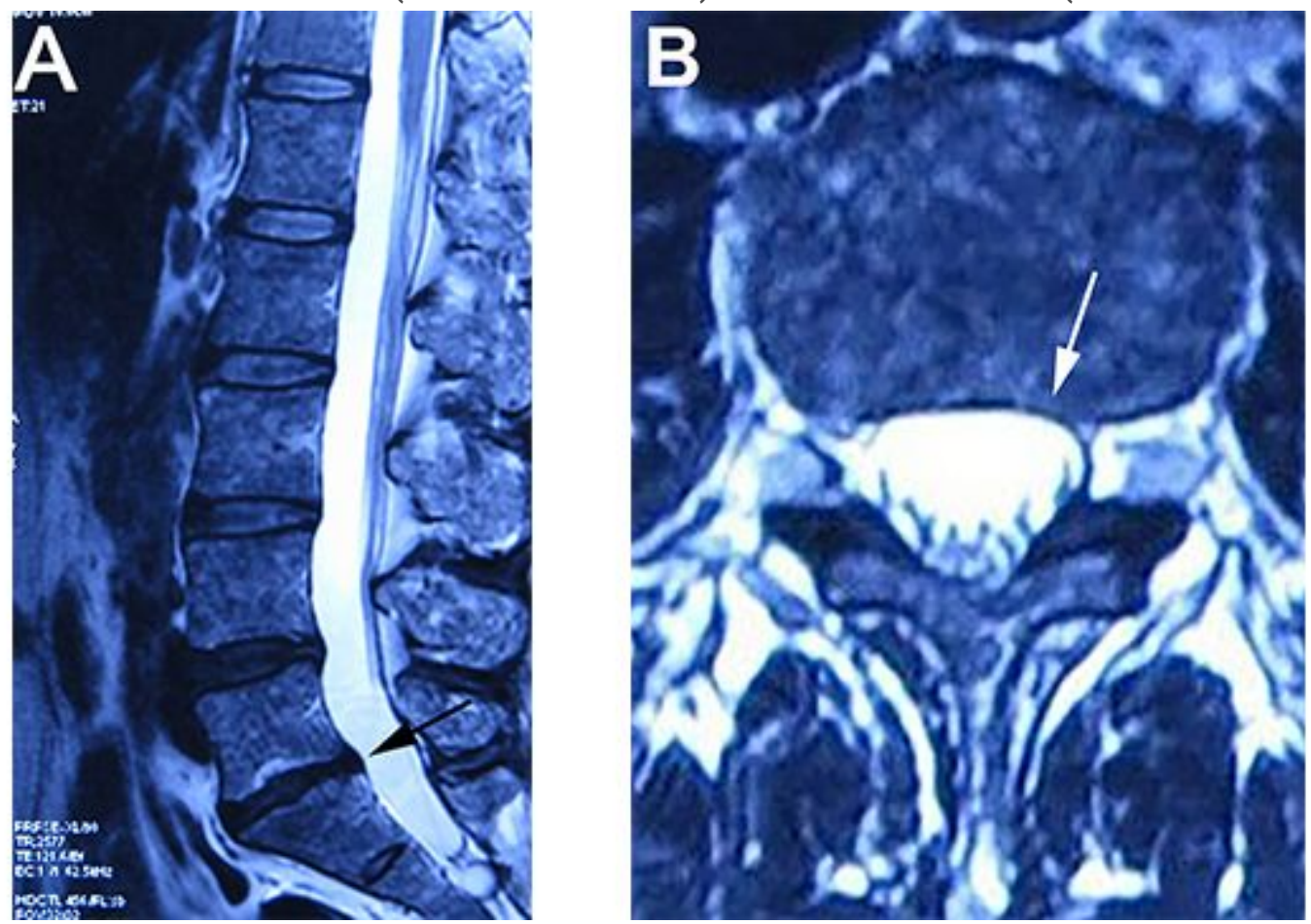

\section{Figure 2}

Follow-up Sagittal (A) and Axial (B) T2-weighted MRI image at the same location two years later. Note the almost complete disappearance of the herniated disc (black and white arrowhead) fragment seen in Fig 
1.

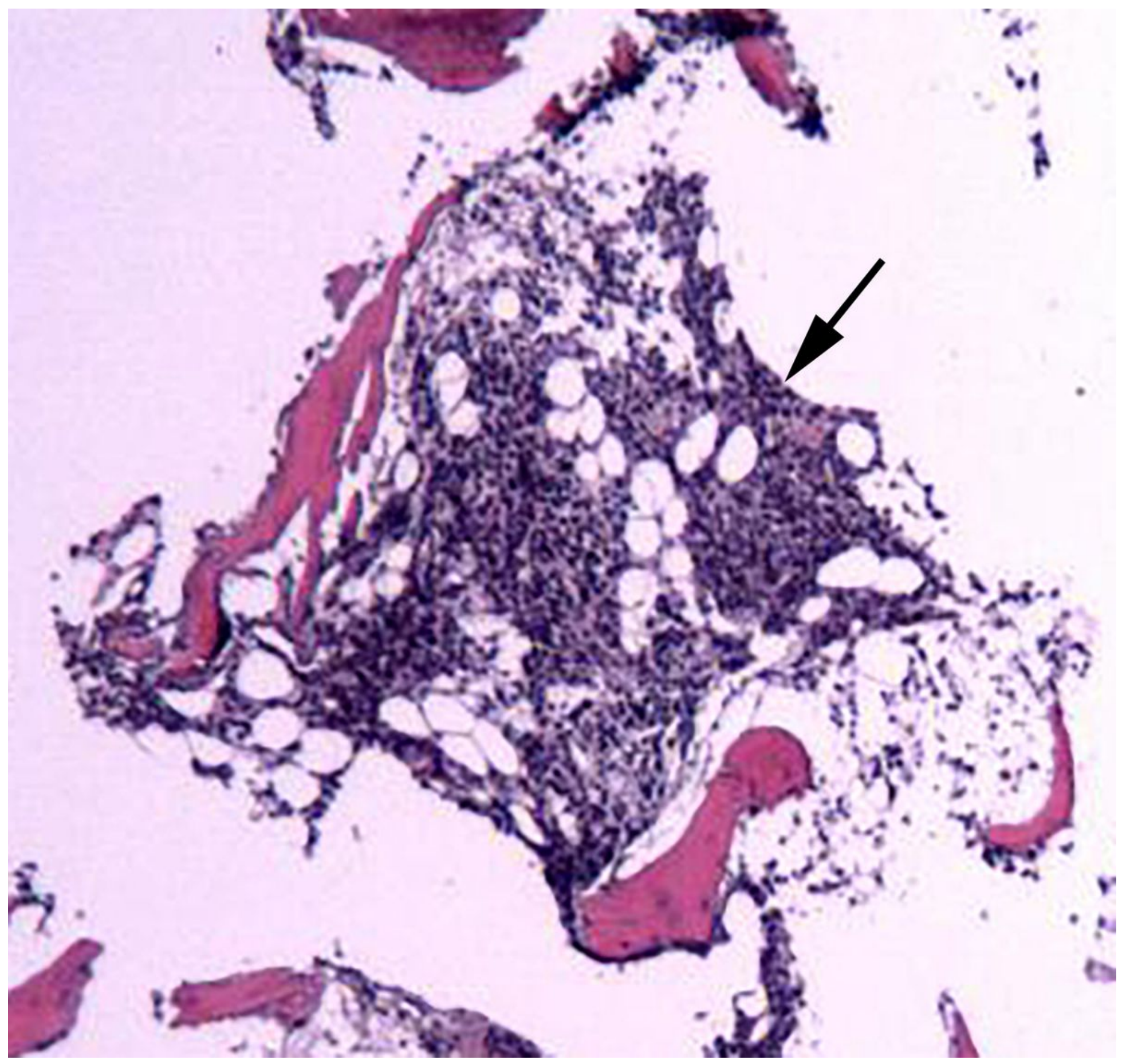

Figure 3

Hematoxylin and eosin stain. Histopathologic analysis revealed diffuse infiltrative plasma cells with mildly pleomorphic round nuclei favoring a plasma cell neoplasm (arrowhead). Magnification 100x. 